\title{
Universiteit
}

Leiden

The Netherlands

\section{Is optimising gout treatment the key to closing the mortality gap in gout patients?}

Brinck, R.M. ten; Moel, E.C. de; Pol, J.A. van der; Beest, S. van; Koning, A. de; Huizinga, T.W.J.

\section{Citation}

Brinck, R. M. ten, Moel, E. C. de, Pol, J. A. van der, Beest, S. van, Koning, A. de, \& Huizinga, T. W. J. (2018). Is optimising gout treatment the key to closing the mortality gap in gout patients? Annals of The Rheumatic Diseases, 77(1).

doi:10.1136/annrheumdis-2017-211638

Version: $\quad$ Not Applicable (or Unknown)

License: $\quad$ Leiden University Non-exclusive license

Downloaded from: https://hdl.handle.net/1887/77721

Note: To cite this publication please use the final published version (if applicable). 


\section{eLetter correspondence}

\section{Is optimizing gout treatment the key to closing the mortality gap in gout patients?}

With great interest we read the Extended report of Fisher et al[1] on the unclosing premature mortality gap in gout and we congratulate the authors on their extensive work. In their populationbased cohort study, the authors found that among patients with gout the level of premature mortality remained unimproved over the past 16 years. However, there are a few issues that, in our opinion, merit attention concerning the conclusions that were drawn from the data:

1. The authors hypothesize that proper urate control could have cardiovascular-metabolicrenal benefits, and thus optimizing gout treatment would reduce mortality. However, the authors have chosen "all-cause mortality" as their outcome, most likely because diseaserelated mortality was not available.[2] In rheumatoid arthritis (RA), the main cause for premature mortality is cardiovascular death, with poor clinical RA status prognostic of premature mortality, and thus the closing mortality gap may very well be due to tighter disease control and improved treatment strategies.[3-5] The authors draw a parallel with rheumatoid arthritis and suggest similar progress could be made with improved gout care. However, only by investigating whether mortality in gout is related to the presence of comorbidities (especially cardiovascular or renal deficits), concomitant risk factors (e.g. smoking), or the actual presence of gout is it possible to conclude that the need of optimizing gout treatment is warranted and will indeed close the premature mortality gap.

2. With the impressive numbers of patients included in the study, we would be interested to see subanalyses for different age categories. In our opinion, it is possible that the proposed effect of gout on all-cause mortality could be quite different between younger (e.g. $<40$ years), middle-aged (40-60 years) and older (e.g. $>60$ years) patients, partly due to the different prevalence of comorbidities between the groups.[6]

3. We have noted a missing label in Table 1 and an incorrect legend in Figure 1. On row 17 of Table 1 ( $3^{\text {rd }}$ row under the subheading "Medication Use") the label is missing. We are wondering to which drug these numbers apply. Furthermore, in Figure 1, the labels in the figure indicate that the lines represent the mortality of the cohorts between 1999-2005 and 2006-2012, whereas in the rest of the paper the studied periods are 1999-2006 and 20072014. This led us to wonder, which periods are correct?

4. We would be interested to know if the authors have data available on the number of gout attacks (or actual urate levels) during the observed period and what the effect on the data would be if this was included in the model. If the conclusions drawn by the authors about the added risk of suboptimal gout treatment on mortality are correct, we would observe that the patients with a low number of gout attacks (as a measure of adequate treatment response) would have lower mortality than the patients with a high number of gout attacks (suboptimal treatment response). This would strengthen the hypothesis on the need for optimizing gout treatment.

5. The American authors have indicated that adherence to medication in gout is only about $10 \%$ in the context of mainly USA-based studies.[7] Since the analyses are in the context of a database from the UK, we wonder whether the context of the authors is directly transferable to the UK-based environment on which the data are based and if nonadherence to gout medication in the UK could indeed be a reason for the mortality gap. 
6. The authors have extensively discussed that optimized gout treatment could have cardiovascular-metabolic-renal benefits and reduce intake of non-steroidal antiinflammatory drugs and glucocorticoids, but that low adherence rates impede these effects and may be related to early mortality. However, it is likely that gout patients would have suboptimal adherence to prescribed medication for other comorbidities as well. Even though the authors correct for the baseline comorbidities, one cannot correct for the effect of adherence to comorbidity related-treatment (both pharmacological and nonpharmacological) over time. Therefore it is better to be careful with the conclusion that adherence to gout treatment, rather than treatment of comorbidities, needs to be further optimized to close the mortality gap.

Nevertheless, the authors have provided substantial data on an important current challenge in rheumatological care and we fully agree that more work needs to be done to reduce the unclosing premature mortality gap in gout patients.

Thanks and kind regards,

R.M. ten Brinck ${ }^{1}$

E.C. de Moel $^{1}$

J.A. van der Pol $^{1}$

S. van Beest ${ }^{1}$

A. de Koning ${ }^{1}$

T.W.J. Huizinga ${ }^{1}$

1. Department of Rheumatology, Leiden University Medical Centre, Leiden, The Netherlands

\section{Address of correspondence:}

R.M. ten Brinck, MD,

Department of Rheumatology C1-R, Leiden University Medical Centre,

PO Box 9600, Leiden 2300RC, the Netherlands.

Telephone: 003171 5265655, E-mail: r.m.ten_brinck@lumc.nl

\section{Footnotes:}

Contributors: All authors were involved in the writing and agreed to the final version of this correspondence.

\section{References:}

1. Fisher MC, Rai SK, Lu N, et al. The unclosing premature mortality gap in gout: a general population-based study. Ann Rheum Dis. 2017 Jan 25. pii: annrheumdis-2016-210588. doi: 10.1136/annrheumdis-2016-210588. 
2. Poole CD, Conway P, Currie CJ. An evaluation of the association between C-reactive protein, the change in C-reactive protein over one year, and all-cause mortality in chronic immune-mediated inflammatory disease managed in UK general practice. Rheumatology (Oxford). 2009 Jan;48(1):7882. doi: 10.1093/rheumatology/ken415.

3. Dadoun S, Zeboulon-Ktorza N, Combescure C, et al. Mortality in rheumatoid arthritis over the last fifty years: Systematic review and meta-analysis. Joint Bone Spine. 2013 Jan;80(1):29-33. doi: 10.1016/j.jbspin.2012.02.005.

4. Sokka T, Abelson B, Pincus T. Mortality in rheumatoid arthritis: 2008 update. Clin Exp Rheumatol. 2008 Sep-Oct;26(5 Suppl 51):S35-61.

5. Agca R, Heslinga SC, Rollefstad S, et al. EULAR recommendations for cardiovascular disease risk management in patients with rheumatoid arthritis and other forms of inflammatory joint disorders: 2015/2016 update. Ann Rheum Dis. 2017 Jan;76(1):17-28. doi: 10.1136/annrheumdis-2016-209775.

6. Huang CF, Liu JC, Huang HC, et al. Longitudinal transition trajectory of gouty arthritis and its comorbidities: a population-based study. Rheumatol Int. 2017 Feb;37(2):313-322. doi: 10.1007/s00296-016-3634-9.

7. De Vera MA, Marcotte G, Rai S, et al. Medication Adherence in Gout: A Systematic Review. Arthritis Care Res (Hoboken). 2014 Oct;66(10):1551-9. doi: 10.1002/acr.22336. 